\title{
Does parental experience of the diagnosis and intervention process differ for children with auditory neuropathy?
}

\author{
Deidrè Stroebel ${ }^{a}$, De Wet Swanepoel ${ }^{a, b, c,{ }^{*}}$ \\ ${ }^{a}$ Department of Speech-Language Pathology and Audiology, University of Pretoria, South Africa \\ ${ }^{\mathrm{b}}$ Ear Sciences Centre, School of Surgery, University of Western Australia, Nedlands, Australia \\ ${ }^{\mathrm{c}}$ Ear Science Institute Australia, Subiaco, Australia \\ * Corresponding author at: Department of Speech-Language Pathology and Audiology, University of \\ Pretoria, c/o Lynnwood and University Road, Hatfield 0002, South Africa. \\ Tel.: +27 12420 4280; fax: +27 124203517 . \\ E-mail address: dewet.swanepoel@up.ac.za (D.W. Swanepoel).
}

\section{ABSTRACT}

Objectives: This study compared parental experience of the audiological diagnosis and intervention process in children with auditory neuropathy spectrum disorder and sensory neural hearing loss.

Method: A matched group survey was used with parents of children with auditory neuropathy spectrum disorder (ANSD) matched with a control group of parents and children with sensorineural hearing loss $(\mathrm{SNHL})$. The two groups were matched in terms of the child's gender, age, amplifications used, social background and utilization of private or public health care sectors. An interview questionnaire, consisting of 45 questions in 6 categories (1. biographic information, 2. experiences of audiological diagnosis, 3. hearing aid benefit, 4. parental experience of the rehabilitation decision making process, 5. parental needs for emotional support and 6. parental needs for information) using a 5-point lickert scale for categories 2 to 7 , was administered by the same audiologist. 
Results: Children with ANSD experienced a significantly longer waiting period from diagnosis to hearing aid fitting $(p=0.025)$ and/or cochlear implantation $(p=0.036)$. Parents of children with ANSD reported significantly different experiences of the diagnostic process $(p=0.001)$ with poorer understanding of the diagnosis and reporting insufficient time allowed for asking questions. During the rehabilitation decision-making process $47 \%$ of parents with ANSD children (vs. $0 \%$ of parents with SNHL children) reported receiving conflicting information. Parents of children with ANSD were also less likely to recommend hearing aids to other parents. Information needs were similar between groups.

Conclusions: Parents of children with ANSD have different experiences and greater uncertainty during the diagnostic and rehabilitation process. Providing regular consultation and structured timelines through the diagnostic process and decisionmaking process may facilitate this process with less uncertainty.

\begin{abstract}
Abbreviations: ANSD, Auditory Neuropathy Spectrum Disorder; SNHL, Sensorineural Hearing Loss; NICU, Neonatal Intensive Care Unit; CAEP, Cortical Auditory Evoked Potentials; ABR, Auditory Brainstem Response; ASSR, Auditory Steady State Response; MVOS, My View on Services.
\end{abstract}

Keywords: Auditory neuropathy spectrum disorder, Sensory neural hearing loss Cochlear implant, Diagnostic audiology 


\section{INTRODUCTION}

The term auditory neuropathy or auditory dys-synchrony is used to describe a form of hearing impairment in which cochlear outer hair cell function is evident, but afferent neural transmission is disordered [1, 2, 3]. The term 'auditory neuropathy spectrum disorder' (ANSD) was adopted more recently as a way of describing its heterogeneous and multifaceted nature [4].

Evidence supports multiple etiologies and multiple locations as the site of lesion in ANSD, ranging from the cochlear receptors or inner hair cells (IHC), to kernicteric deposits anywhere from the spiral ganglion fibres to the brainstem, to a paucity of myelinated fibres in the VIIIth nerve $[2,3]$.

By clinical definition, patients with this disorder have normal otoacoustic emissions (OAE's) and/or cochlear microphonic (CM) potentials, but exhibit an absent or severely abnormal auditory brainstem response (ABR) beyond the expected for the degree of hearing loss $[1,2,3,5,6]$. Although the diagnosis is clear with an absent $A B R$, no clear guideline exists on what exactly defines an abnormal $A B R$ in cases of ANSD but it includes abnormal wave morphology with ABR thresholds significantly elevated above the expected degree of hearing loss [6].

The degree of hearing loss found in ANSD patients range from mild to profound. Clinical presentation in ANSD typically involves inordinate difficulty listening in noise, possible fluctuations in hearing over time, delayed speech and language development, and speech perception performance that are not easily predicted based on the level of residual hearing $[3,5,7]$. 
Variation is typical of ANSD patients and may relate to time of onset, underlying mechanisms, genetics, possible risk factors, ability to understand speech and changes over time. Some patients display no overt delays or auditory complaints until adulthood or in some cases until MEMR or ABR testing is completed. On the other end of the spectrum patients may display an apparent total lack of sound awareness, reflected in their severely affected communication and speech production abilities [8]. Most patients fall between these two extremes, showing inconsistent auditory responses with best responses in quiet and poorest in noise [5, $6,7]$.

In light of the variability inherent to ANSD, families may experience contradicting information regarding the diagnosis, choices in communication, amplification and intervention for their child $[9,10$. In the case of children with ANSD and their families, this process is intensified because of the complexity and heterogeneity inherent to the condition [6].

Most of the documented research on the experiences and support of families of children with hearing loss is focused on children's early stages of development [11]. The impact of deafness on the family, including the various challenges associated with raising a child with hearing loss and families' support needs have been well documented, but little has been documented about the specific experiences, perceptions and needs of parents with ANSD children. In a qualitative narrative study by Uus, Young \& Day (2012), experiences of ANSD parents were described. The diagnosis of ANSD in this study was made following newborn hearing screening. It 
was found that these parents did not prioritize hearing very highly at the time of diagnosis because of other medical problems. ANSD was not seen as a standalone diagnosis but as part of a bigger picture as all of the ANSD babies were graduates from the NICU [12]. The fact that multiple risks and developmental delays are associated with ANSD mean there are additional factors that influence the parental experiences [13]. Investigating parental experiences for children with ANSD compared to those with SNHL may inform early health provider and parent interactions to be responsive to particular needs. The aim of this study therefore, was to compare parental experiences of the audiological diagnosis and intervention process in children with SNHL and ANSD.

\section{METHODS}

This study was conducted with parents of children who attended a centre for hearing impaired children. Children at this centre are exposed to an auditory/oral method of communication that aims to empower parents and children to manage in the mainstream environment. Institutional ethical committee approval was obtained before data collection was initiated.

A matched-group survey was used with parents of children with ANSD matched with a control group of parents of children with SNHL. 


\subsection{Study population}

Two groups of 15 parents each were sampled, one with children with ANSD and the control group with children with SNHL. The two groups were matched in terms of the child's gender, age, amplification used, social background and utilization of private or public health care sectors (Table 1).

Table 1. Characteristics of particiapnts (parents and children)

\begin{tabular}{|c|c|c|}
\hline CHARACTERISTICS & ANSD $(n=15)$ & SNHL $(n=15)$ \\
\hline \multicolumn{3}{|c|}{ Relationship with child with hearing loss } \\
\hline Father & 1 & 2 \\
\hline Mother & 13 & 13 \\
\hline Grandparent & 1 & - \\
\hline \multicolumn{3}{|l|}{ Highest qualification } \\
\hline Primary school (grade 1-7) & 1 & 2 \\
\hline High school (grade 8 - 12) & 4 & 4 \\
\hline Matric completed & 2 & 3 \\
\hline Tertiary education & 8 & 6 \\
\hline \multicolumn{3}{|l|}{ Enrolled in parent guidance program } \\
\hline At time of study & 10 & 10 \\
\hline Discharged from program & 5 & 5 \\
\hline \multicolumn{3}{|l|}{ Medical service provider } \\
\hline State & 6 & 6 \\
\hline Private & 9 & 9 \\
\hline \multicolumn{3}{|l|}{ Ages of children at time of survey } \\
\hline Average & 5.9 years $(S D=2.8)$ & 6.1 years $(S D=2.9)$ \\
\hline Range & $1.10-12.3$ years & $2-12.3$ years \\
\hline \multicolumn{3}{|l|}{ Risk factors } \\
\hline Unknown & 2 & 8 \\
\hline Heredity & & 5 \\
\hline Prematurity ( $\leq 34$ weeks) & 12 & \\
\hline Blood transfusions & 8 & \\
\hline Loss of oxygen & 6 & \\
\hline Other & - & 2 \\
\hline \multicolumn{3}{|l|}{ Newborn Hearing Screening } \\
\hline Yes & 10 & 5 \\
\hline
\end{tabular}




\begin{tabular}{lcc}
\hline No & 4 & 9 \\
Unsure & 1 & 1 \\
Average age at time of identification & 1.4 years $(\mathrm{SD}=1.1)$ & 1.4 years $(\mathrm{SD}=1.1)$ \\
Average age at time of hearing aid fitting & 1.9 years $(\mathrm{SD}=1.3)$ & 1.7 years $(\mathrm{SD}=1.1)$ \\
Average age of cochlear implant & & \\
First & 3.9 years $(\mathrm{SD}=1.6)$ & 2.8 years $(\mathrm{SD}=1.9)$ \\
Second & 4.10 years $(\mathrm{SD}=2.0)$ & 3.0 years $(\mathrm{SD}=1.5)$ \\
Amplification & & 6 \\
Bilateral hearing aids & 4 & 6 \\
Bilateral cochlear implants & 6 & 3 \\
Bimodal & 3 & - \\
Unilateral hearing aid & 1 & - \\
None & 1 & \\
\hline
\end{tabular}

Table 1 describes the demographic characteristics of the families who participated in this survey.

\subsection{Procedures}

An interview questionnaire, consisting of 45 questions divided into six subcategories (biographic information, experiences of audiological diagnosis, hearing aid benefit, parental experiences of the rehabilitation decision making process, parental needs for emotional support and parental needs for information) was administered. The same independent audiologist administered the questionnaire to all parents/caregivers. These interviews were conducted in a personal or telephonic interview. On average an interview was conducted in 20 minutes. Instructions about the completion of the questionnaire was conveyed to each parent/caregiver and informed consent was required by each participant before commencing. 
Questions were derived and adopted from an existing questionnaire, namely the MVOS (My View On Services) [14]. Additional questions were referred from qualitative report on parents whose infants have been identified with ANSD [12]. Fourteen questions were asked to gain demographic and case history information. A 5-point Lickert scale was implemented for the remaining 31 questions in order to obtain information about the parents'/caregivers perceived experiences, opinions and needs. The responses were evaluated on a continuum of strongly disagree (1), disagree (2), neutral (3), agree (4) and strongly agree (5).

\subsection{Data analysis}

Data collected from this survey was tabulated on an Excel sheet and all statistical analyses were performed using SAS version 9.3. The data were analysed descriptively to yield percentages and frequency distributions within the two groups. The Exact $\mathrm{Chi}^{2}$ test (using Monte Carlo simulation) was used to investigate possible statistically significant association between the responses of the two groups. Statistical significance was set at a probability level of 0.05 . 


\section{RESULTS}

\subsection{Experience of audiological diagnosis}

Seven questions concerned the diagnostic process (Figure 1), covering aspects of conveying the diagnosis, information provision, and understanding of diagnosis after feedback and guidance for future actions (Online Appendix 1).

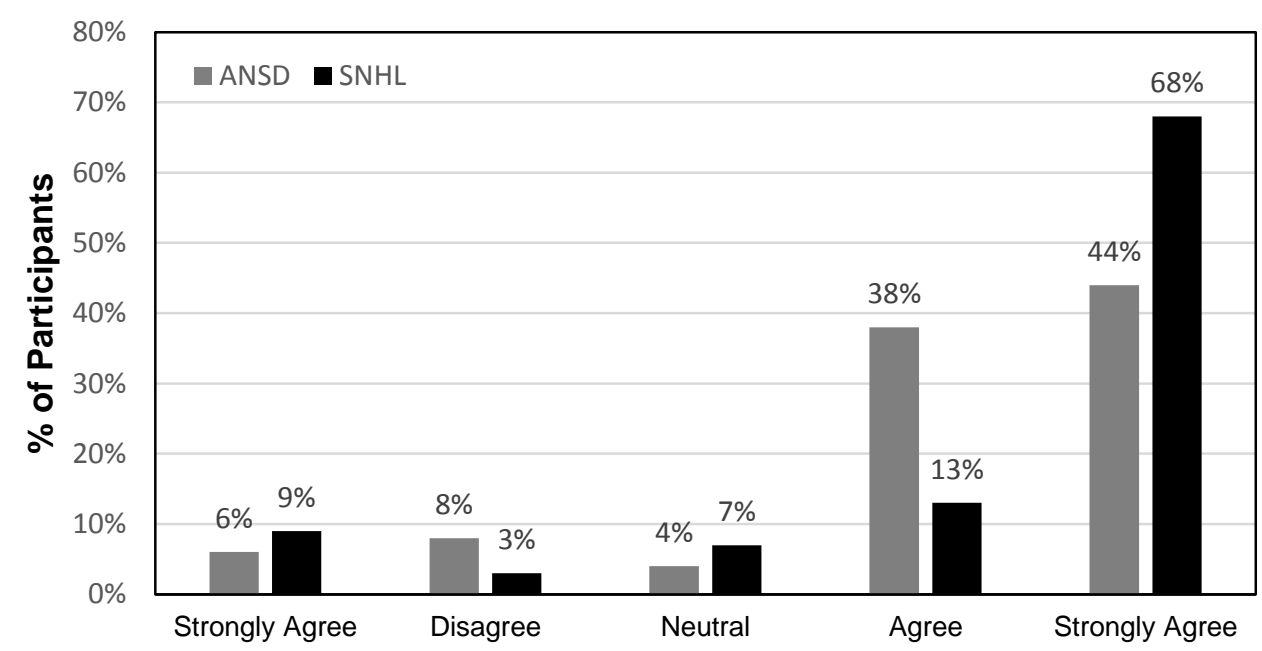

Figure 1. Parental experience related to the diagnostic audiological process (summarised from seven questions; $\mathrm{n}=210$ responses). Strongly Disagree $=$ most negative experience and Strongly Agree $=$ most positive experience .

Overall parental experience of the diagnostic process (Figure 1) was significantly different between parents of children with SNHL and ANSD $(p=0.001)$. Across individual questions related to the diagnostic process significant differences were evident for two of these (2/7). Parents of children with ANSD indicated poorer understanding of the hearing loss diagnosis $(p=0.012)$ than those with SNHL. 
Parents of children with ANSD were also more likely $(p=0.032)$ to report insufficient time allowed for asking questions during the diagnostic process.

Two additional questions related to parental experience of delays in diagnosis, although not statistically significant, indicated that twice as many parents of children with ANSD agreed or strongly agreed (66\%) that the process was lengthy compared to parents of children with SNHL (33\%).

Furthermore parents of children with ANSD reported a significantly larger number of diagnostic audiological sessions $(p=0.015)$ required to make a final diagnosis. More than half (53\%) of the ANSD group reported more than five diagnostic sessions before a final diagnosis was made $(7 \%$ required five sessions, $27 \%$ required two sessions and $13 \%$ required a single session). In contrast almost half (40\%) of the SNHL group required only one session for the diagnosis $(13.3 \%$ required two sessions, $13.3 \%$ required three, $20 \%$ required four and $13.3 \%$ required more than five sessions).

The majority (80\%) of the SNHL parent group strongly agreed that hearing loss was their only concern about their child at the time of diagnosis, whilst $7 \%$ was neutral and $13 \%$ had some other concerns. Half $(53 \%)$ of the ANSD group strongly agreed that hearing loss was their only concern, followed by $27 \%$ who agreed and the remaining $21 \%$ was equally divided across neutral, disagreeing and strongly disagreeing. 


\subsection{Hearing aid benefit}

Three questions concerned the benefit derived from hearing aids (Figure 2), covering aspects of the child's improved reaction to sound and improved speech understanding (Online Appendix 1).

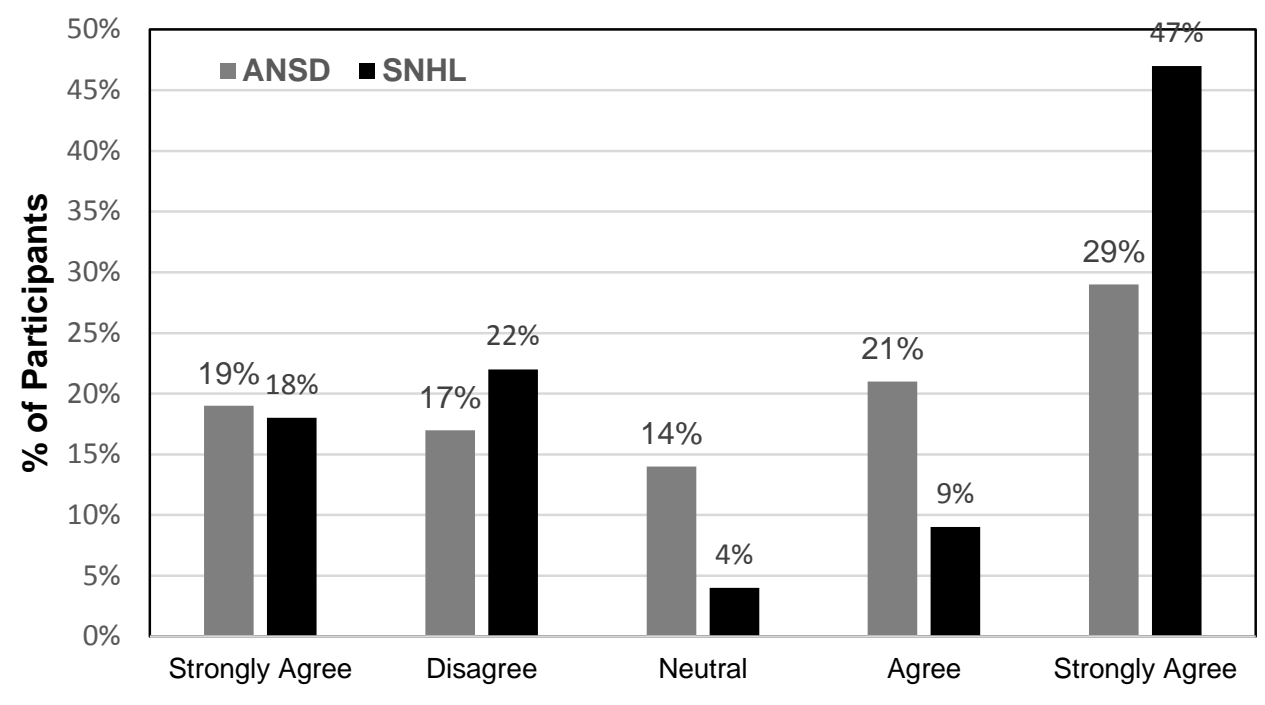

Figure 2. Perceived hearing aid benefit (summarised from three questions; $\mathrm{n}=87$ responses). Strongly Disagree $=$ least benefit and Strongly Agree $=$ most benefit

No significant difference $(p=0.149)$ was evident for the perceived benefit derived from hearing aids between the two groups.

$40 \%$ of the SNHL group used bilateral cochlear implants and $20 \%$ were using bimodal amplification. $40 \%$ of the SNHL group used hearing aids with success. $60 \%$ of these parents did perceive an improvement in their children's reaction to sound 
with hearing aids with $47 \%$ experiencing an improvement in speech understanding, before cochlear implantation was considered for appropriate candidates.

In the ANSD group the same percentage $(40 \%)$ of children used bilateral cochlear implants and bimodal amplification, 27\% used binaural hearing aids, $7 \%$ used a unilateral hearing aid and $7 \%$ used no amplification. $58 \%$ of these parents perceived an improvement in their children's reaction to sound with hearing aids and $50 \%$ perceived an improvement in speech understanding, before cochlear implantation was considered for appropriate candidates.

Only $27 \%$ of the ANSD group indicated that they would strongly recommend the use of hearing aids to other parents as opposed to $60 \%$ of the SNHL group.

\subsection{Experience of the habilitation decision making process}

Five questions related to parental experiences and concerns during the habilitation decision making process (Figure 3). These included parental concerns about the use of hearing aids, the process of decision making about amplification, receiving conflicting information during this process, too many professionals' involved and professional's respect of the parent's role during this process (Online Appendix 1).

There was no significant difference $(p=0.2274)$ between the reported experience of the decision making process of these two parent groups. Nonetheless $47 \%$ of the ANSD group reported receiving conflicting information from professionals during the 


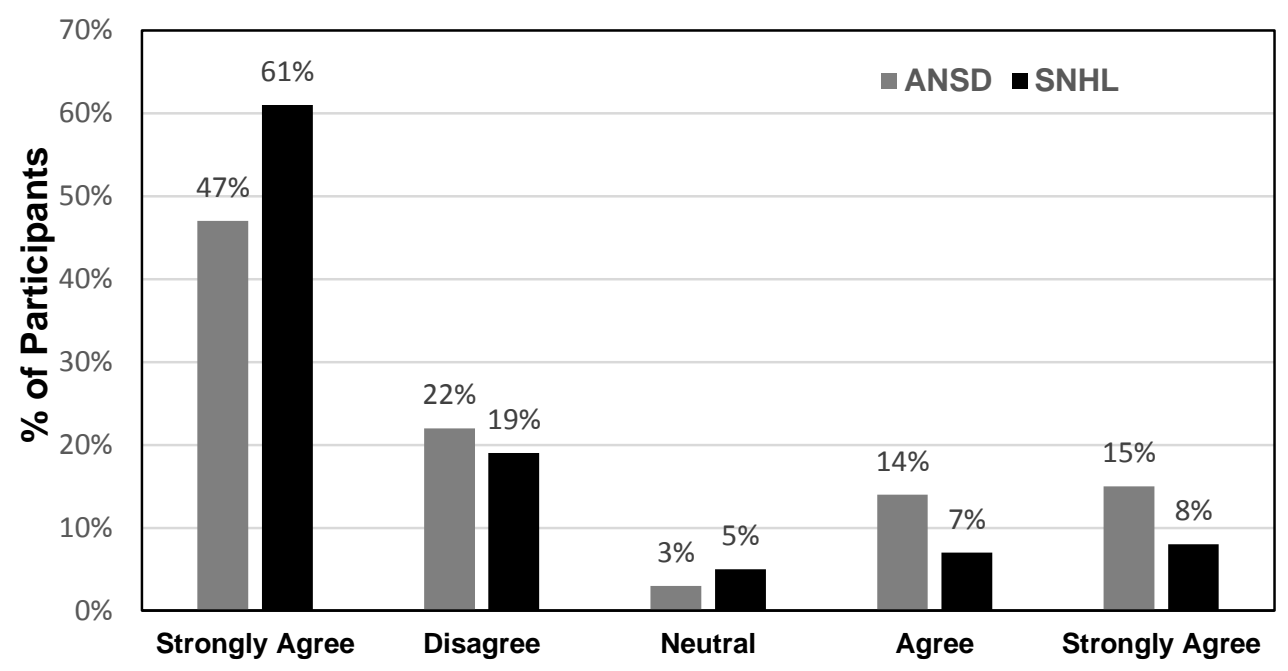

Figure 3. Parental experiences of the rehabilitation decision making process (summarised from five related questions; $\mathrm{n}=148$ responses). Strongly Disagree $=$ most positive experience and Strongly Agree = most negative experience.

amplification decision making process as opposed to none of the SNHL group $(p=$ 0.07).

Two thirds (67\%) of the ANSD parent group indicated the amplification decision making process not being difficult as opposed to $80 \%$ of the SNHL parent group. A significant difference $(p=0.025)$ was evident between these two groups in the time from diagnosis to hearing aid fitting and from diagnosis to first cochlear implant $(p=0.036)$ as seen in Table 1.

After the final decision on amplification (hearing aids and cochlear implantation) was made, $7 \%$ of the ANSD group remained neutral about the consistent use of amplification, $7 \%$ agreed to the consistent use of the amplification and $86 \%$ strongly agreed that their children consistently use their amplification. In the SNHL parent 
group, all parents $(93 \%=$ strongly agreed, $7 \%$ agreed $)$ reported that their children wanted to use their amplification consistently.

\subsection{Need for emotional support}

Seven questions concerned the parental need for emotional support (Figure 4), including opportunities to meet with other parents, to be part of a support group, need to talk to someone outside the family and someone to talk to on how to handle and cope with a hearing impaired child (Online Appendix 1).

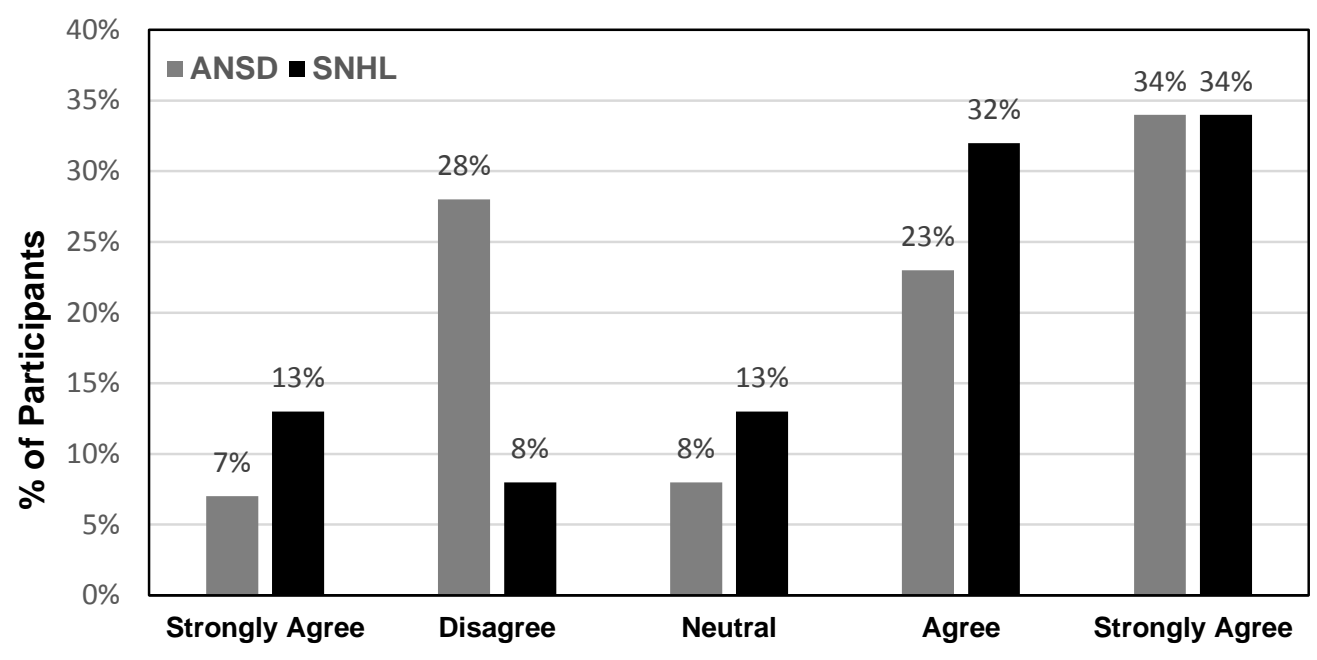

Figure 4. Parental need for emotional support (summarised from seven related questions; $n=$ 209 responses). Strongly Disagree $=$ minimum need for support and Strongly Agree $=$ greatest need for support.

No significant differences were evident in the two groups of parents' responses regarding the need for emotional support $(p=0.051)$.

On an individual question the SNHL group felt a greater need to talk to someone on how to handle and cope with their hearing impaired children $(p=0.0229)$. 


\subsection{Parental need for information}

Six questions concerned the parental need for information (Figure 5), including aspects such the need for information about hearing loss, expectations for the future, communication options, intervention services and educational options (Online Appendix 1).

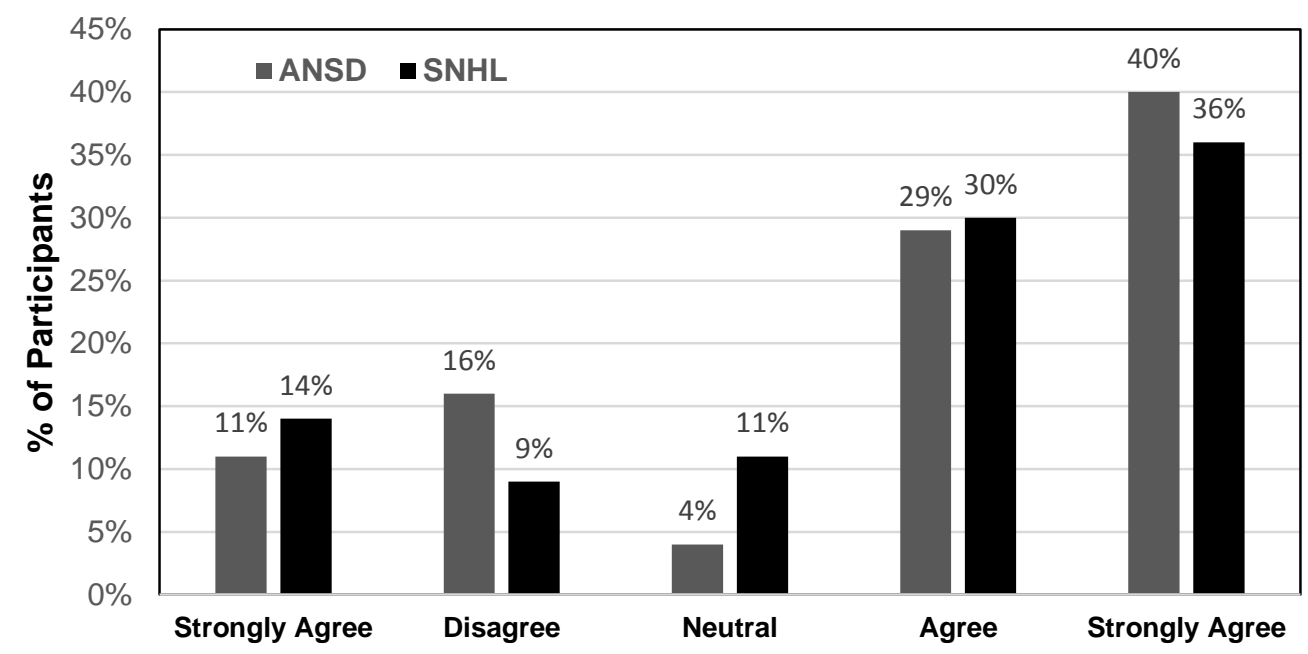

Figure 5. Parental need for information (summarised from six related questions; $n=180$ responses). Strongly Disagree $=$ the minimum need for information and Strongly Agree $=$ greatest need for information.

No statistical differences were evident in the two groups of parents' responses on need for information $(p=0.307)$. 


\section{DISCUSSION}

Parents of ANSD children reported experiencing a poorer understanding of the diagnosis and that insufficient time was allowed for asking questions. Close to half (47\%) of the ANSD parents reportedly received conflicting information from professionals during this process. Obtaining information is an important part of parental coping and the decision-making processes towards adjusting to their child's hearing loss [11]. In diagnoses of ANSD, families face additional challenges above and beyond the diagnosis of a hearing loss. Due to the range of clinical presentations in ANSD there are often uncertainties at the time of diagnosis with resultant complexities associated with management options $[6,9,15]$. This is reflected in the poorer understanding of the ANSD diagnosis and the issue of conflicting information reported by parents in the current study.

Considering the heterogeneous nature of the disorder and range of functional outcomes, no definitive predictions regarding 'expected' auditory behaviours can be made until additional diagnostic information has been obtained and as a result there is an inherent amount of uncertainty that accompany ANSD and may not be typical to $\mathrm{SNHL}[16,17,12]$. As a result professionals should be sensitive to inform families that additional test procedures and examinations may be required for definitive diagnosis and etiological evidence (such as an MRI to rule out cochlear nerve deficiency) [16, 15]. Roush (2011) emphasises the need for families to have a timeline for management during the first year, including the need for medical evaluations, enrolment in early intervention programmes, establish behavioral threshold (6-7 months of age) and repeat ABR assessments. Parents need to 
know that decisions regarding amplification (hearing aids or cochlear implantation) may need to be deferred until behavioral audiometric thresholds can be established. With these guidelines communicated to the parents from the outset, may lessen the impact of the uncertainty surrounding the diagnosis and management $[4,15,16]$.

Significantly more diagnostic sessions were required to make the final diagnosis in ANSD than SNHL in the current study with parents experiencing the diagnostic process as prolonged. Diagnosing ANSD should be straightforward but determining the auditory capacity in the infant period however is more challenging as patients with ANSD vary greatly $[5,15,17,18]$. Clinical characteristics include pure tone thresholds ranging from normal to profound levels, disproportionately poor speech recognitions abilities for the degree of hearing loss, difficulty hearing in noise; and impaired temporal processing $[2,5,19,20]$.

Unlike SNHL, threshold estimation is not possible with Auditory Brainstem Response (ABR) or Auditory Steady State Response (ASSR) $[1,5,15]$. As a results developmentally appropriate behavioral measures, which typically may only be possible after the age of 6 months must be used to determine hearing thresholds [17]. Waiting for the child to be old enough for these behavioral assessments, prolong the process, as reported by the parents in this study. Since a significant proportion of children with permanent hearing loss have ANSD, with estimates between $10 \%$ and $20 \%[5,21]$ audiological diagnosis should rely on appropriate test batteries to accurately determine ANSD as soon as possible [5]. Following recommended guidelines such as those developed at the ANSD consensus conference may facilitate more consistency across practices $[4,16]$. 
Cortical evoked potentials may become useful in cases where behavioural methods are inconclusive $[1,22,23]$. To date however cortical auditory evoked potentials have mostly been employed in laboratory settings, rather than in clinical settings and are not consistently included within a test battery for assessing auditory function [24] Using CAEP potentials in a clinical setting, may however provide hearing threshold estimates at earlier ages allowing for appropriate early intervention strategies at a younger age. This may lessen the uncertainty and frustrations experienced by parents who await closure on the threshold determination process so that intervention can commence.

Delay between initial hearing loss diagnosis and hearing aid fitting or first cochlear implantation was significantly longer for ANSD compared to SNHL children. Hood (2013) and Attias (2013) also reported a significant difference in age at time of cochlear implantation between SNHL and ANSD children, with the ANSD children an average of one year older at the time of first implantation. As far as possible accurate initial diagnosis along with timely determination of hearing thresholds should be prioritized to ensure hearing aid fitting and/or cochlear implantation as early as possible. This is important for optimal auditory and language outcomes [27, 28, 29].

Parents of ANSD children reported significantly less need to talk to someone about their hearing impaired child. This seems counter-intuitive, but may be related to several possible reasons bearing in mind the limitations of the small sample size. The time immediately after the diagnosis is perceived as the most stressful for parents with the diagnosis of a childhood disability [30]. A marked relief however is experienced at the time of intervention, for example with hearing aid fitting and/or a 
cochlear implantation [30]. Parents of children with ANSD may experience this more acutely after the range of uncertainties during the diagnostic process. As a result these parents, whose children have all received assistive devices, may experience a lesser subsequent need for emotional support. Uus et al. (2011) suggested that parents of ANSD children also experience a more traumatic perinatal period with more anxiety and worry about their child's survival and long-term health and development. The implications of ANSD by comparison and contrast with what they have already experienced, may therefore be a smaller detail against the backdrop of this bigger reality.

Parents of both groups experienced similar needs for information with regards to hearing loss, expectations for the future, communication options, intervention services and educational options. Parents continue to experience a need for information as their concerns emerge on aspects of education and future opportunities for their children with hearing loss and concerns regarding parenting a deaf or hard-of-hearing child with additional needs [11]. The fact that parents in the current study had all enrolled at the same early intervention centre soon after diagnosis may also have ensured that there was no difference in the experienced need for information.

\section{CONCLUSIONS}

There were five predominant findings in this study: (1) parents of ANSD children had a significantly different experience of the diagnostic process compared to parents with SNHL children; (2) almost half the parents of ANSD children reported receiving 
conflicting information from professionals during the amplification decision making process as opposed to none in the SNHL group; (3) ANSD children had significantly longer wait times from diagnosis to hearing aid fitting and for cochlear implantation; (4) indicated significantly less need to talk to someone about their hearing impaired child; (5) both groups of parents had the same need for information with regards to hearing loss, expectations for the future, communication options, intervention services and educational options.

A clear timeline for management during the first year, including the need for medical evaluations, enrolment in early intervention programmes, establishing behavioural threshold (6 - 7 months of age) and repeat ABR assessments, may guide the parent of an ANSD child through the diagnostic process and decision making about amplification and habilitation with less uncertainty. As professionals working with these families, it is important to share information based on the best available scientific evidence, whether it may be during the early stages of diagnosis, decision making about amplification or at a much later stage about educational choices and future opportunities.

\section{ACKNOWLEDGEMENTS}

The authors acknowledge and thank the Carel du Toit Centre for Hearing Impaired Children, and thank the families who participated in this study. 


\section{REFERENCES}

1. Rance, G., Cone-Wesson, B., Wunderlich, J., \& Dowell, R. (2002). Speech perception and cortical event-related potentials in children with auditory neuropathy. Ear \& Hearing, 23(3), 239 - 253.

2. Berlin, C.I., Hood, L., Morlet, T., Rose, K., \& Brashers, S. (2003). Auditory Neuropathy/Dys-synchrony: Diagnosis \& Management. Mental Retardation and Developmental Disabilities Research Reviews, 9, 225 - 231.

3. Starr, A., Picton, T.W., Sininger, Y., Hood, L.J., \& Berlin, C.I. (1996). Auditory Neuropathy. Brain, 119, 741 - 753.

4. Guidelines Development Conference on the Identification and Management of Infants with Auditory Neuropathy. (2008).

5. Rance, G., \& Starr, A. (2011). Auditory Neuropathy/Dys-Synchrony Type Hearing Loss. In R. Seewald \& A.M. Tharpe, Comprehensive Handbook of Pediatric Audiology (pp. 225 - 242). San Diego: Plural Publishing.

6. Norrix, L.W. \& Velenovsky, D.S. (2014). Auditory Neuropathy Spectrum Disorder: A Review. Journal of Speech, Language, and Hearing Research, $57,1564-1576$.

7. Kraus, N., Bradlow, A.R., Cheatham, M.A., Cunningham, J., King, C.D., Koch, D.B., Nicol, T.G., McGee, T.J., Stein, L.K. \& Wright, B.A. (2000). 
Consequences of Neural Asynchrony: A Case of Auditory Neuropathy. Journal of the Association for Research in Otolaryngology, 1, 33 - 45.

8. Hood, L.J. (2011). Variations in Auditory Neuropathy Spectrum Disorder: Implications for Evaluation and Management. Seminars in Hearing, 32, 117 $-122$.

9. Olsen, S. (2013). Supporting Families of Children with ANSD. A Sound Foundation Through Early Amplification 2013: 6th /international Pediatric Conference, Chicago.

10. Des Georges, J. (2003). Family Perceptions of Early Hearing, Detection and Intervention Services: Listening to and Learning form Families. Mental Retardation Development Disability Research Review, 9(2), 89 - 93.

11. Jamieson, J.R., Zaidman-Zait, A., \& Poon, B. (2011). Family Support Needs as Perceived by Parents of Preadolescens and Adolescents Who are Deaf or Hard of Hearing. Deafness \& Education International, 13(3), 110-130.

12.Uus, K., Young, A., \& Day, M. (2012). Auditory neuropathy spectrum disorder in the wider health context: Experiences of parents whose infants have been identified through newborn hearing screening programmes. International Journal of Audiology, 51, 186 - 193.

13. Ching, T., Harvey, D., Marnane, V., Hou, S., Day, J., Seeto, M., Crowe, K., Street, L., Thomson, J., Van Buynder, P., Zhang, V., Wong, A., Burns, L., Flynn, C., Cupples, L., Cowan, R.S., Leigh, G., Sjahalam-King, J., \& Yeh, A. 
(2013). Outcomes of Early- and Late-Identified Children at 3 years of Age: Findings From a Prospective Population-Based Study. Ear \& Hearing, 34(5), $535-552$.

14. Young, A., Gascon-Ramos, M., Campbell. M., \& Bamford, J. (2009). The Design and Validation of a Parent-Report Questionnaire for Assessing the Characteristics and Quality of Early Intervention Over Time. The Journal of deaf studies and Deaf Education, 422 - 435.

15. Roush, P. (2011). Children with Auditory Neuropathy Spectrum Disorder. In R. Seewald \& A.M. Tharpe, Comprehensive Handbook of pediatric Audiology. San Diego: Plural Publishing.

16. NHS Newborn Hearing Screening Programme. (2013). Guidelines for the assessment and management of auditory neuropathy spectrum disorder in young infants, Version 2.2. Retrieved from http://hearing.screening.nhs.uk/audiologypublic

17. Roush, P., Frymark, T., Venediktov, R., \& Beverly Wang. (2011). Audiologic Management of Auditory Neuropathy Spectrum Disorder in Children: A systematic Review of the Literature. American Journal of Audiology, 20, 159 $-170$.

18. Rance, G. (2005). Auditory neuropathy/dys-synchrony and its perceptual consequences. Trends in Amplification, 9(1), 1 - 43. 
19.Buchman, C.A., Roush, P.A., Teagle, H.F.B., Brown, C.J. Zdanski, C.J., \& Grose, J.H. (2006). Auditory Neuropathy Characteristics in Children with Cochlear Nerve Deficiency. Ear and Hearing, 27, 399 - 408.

20.Rance, G., Beer, D.E., Cone-Wesson, B., Sheppard, R.K., Dowell, R.C., King, A.K., \& Clark, G.M. (1999). Clinical findings for a group of infants and young children with auditory neuropathy. Ear and Hearing, 20, 238 - 252.

21.Swanepoel, D., Johl, L., \& Pienaar, D. (2013). Childhood hearing loss and risk profile in a South African Population.

http://www.ncbi.nim.nih.gov/m/pubmed/23266158/, 1 - 18.

22.Sharma, A., Cardon, G., Henion, K., \& Roland, P. (2011). Cortical maturation and behavioral outcomes in children with auditory neuropathy spectrum disorder. International Journal of Audiology, 50, 98 - 106.

23.Pearse, W., \& Martin, R.L. (2009). On auditory neuropathy, aka auditory neuropathy spectrum. The Hearing Journal, 62(2), 38 - 39.

24. Hall, J.W., Bantwal, A.R., Ramkumar, V., \& Chhabria, N. (2011).

Electrophysiologic Assessment of Hearing With Auditory Middle Latency and Auditory Late Responses. In R. Seewald \& A.M. Tharpe, Comprehensive Handbook of Pediatric Audiology (pp. 449 - 482). San Diego: Plural. 
25.Hood, L.J., Morlet, T., \& Berlin, C.I. (2013). Management and Outcomes of PAtients with Auditory Neuropathy/Dys-synchrony. 11th EFAS Congress Budapest.

26. Attias, J., Raveh, E., Aviva F-V., Peled, M., \& Efrati, M. (2013). The Varieties of Auditory Neuropathy: Clinical and Longterm Follow-up. 11th EFAS Congress Budapest .

27. Cardon, G. \& Sharma, A. (2013). Central auditory maturation and behavioral outcome in children with auditory neuropathy spectrum disorder who use cochlear implants. International Journal of Audiology, Early Online: 1 - 10.

28. Kirk, K., Miyamotot, R., Lento, C., Ying, E., O'Neill, T., \& Fears, B. (2002). Effects of age at implantation in young children. Annals of Otology, Rhinology and Laryngology, 11169 - 73.

29. Robbins, A.M., Bollard, P.M., \& Green, J. (1999). Language development in children implanted with the Clarion cochlear implant. American Journal of Otology, Rhinology and Laryngology, 108, 113 - 118.

30.Burger, T., Spahn, C., Richter, B., Eissele, S., Lohle, E., \& Bengel, J. (2005). Parental Distress: The Initial Phase of Hearing aid and Cochlear Implant Fitting. American Annals of the Deaf, 150 (1), 5 - 10. 
Appendix A. Supplementary data

\section{CHILDREN WITH HEARING LOSS \\ PARENT QUESTIONNAIRE}

Please complete the following by selecting ONE appropriate answer at each question

\section{Section 1: Biographic Information}

Date of interview:

1. What is the sex of your child with the hearing loss?

Male

$\square$ Female

2. What is your relationship with the child with the hearing loss?
Father
Foster Parent
Provider/Supporter
\begin{tabular}{|l} 
Mother \\
Stepparent
\end{tabular}

3. What is the date of birth of your child with the hearing loss?

\begin{tabular}{|c|c|c|}
\hline Year & Month & Day \\
\hline & & \\
\hline
\end{tabular}

4. What is your highest qualification?

\begin{tabular}{|l|l|}
\hline None & \\
\hline Primary School (Grade 1-7) & \\
\hline High School (Grade 8-11) & \\
\hline Matric completed & \\
\hline Tertiary qualification & \\
\hline
\end{tabular}

5. Are you and your child enrolled in a parent program for intervention of hearing loss?
Yes
$\square$ No

6. How long have you attended this program?

\begin{tabular}{|c|c|}
\hline Years & Months \\
\hline & \\
\hline
\end{tabular}

7. What do you think is the cause of your child's hearing loss?

\begin{tabular}{|l|c|}
\hline Unknown \\
\hline Heredity \\
\hline Prematurity \\
\hline$\bullet \quad$ Term of pregnancy \\
\hline$\bullet \quad$ Birth Weight \\
\hline$\bullet \quad$ Apgar Scores \\
\hline$\bullet \quad$ Blood transfusions \\
\hline$\bullet \quad$ Loss of Oxygen \\
\hline
\end{tabular}


8. Which medical service provider do you use?

\begin{tabular}{|l|l|}
\hline Private & \\
\hline Public/state & \\
\hline
\end{tabular}

\section{Section 2: Experiences of audiological diagnosis}

9. How old was your child when his/her hearing loss was diagnosed?

\begin{tabular}{|c|c|}
\hline Years & Months \\
\hline & \\
\hline
\end{tabular}

10. Was your child's hearing tested at birth?

\begin{tabular}{|l|l|}
\hline Yes & \\
\hline No & \\
\hline Unsure & \\
\hline
\end{tabular}

11. If no, who referred you for a test?

\begin{tabular}{|l|l|}
\hline Self & \\
\hline Pediatrician & \\
\hline Family member/friend & \\
\hline Other (please specify & \\
& \\
\hline
\end{tabular}

12. Who made the diagnosis of your child's hearing loss?

\begin{tabular}{|l|l|}
\hline Audiologist & \\
\hline Pediatrician & \\
\hline Ear-, Nose- \& Throat & \\
Specialist & \\
\hline Other (please specify & \\
& \\
\hline
\end{tabular}

13. The diagnosis of your child's hearing loss was your main concern at the time.

\begin{tabular}{|c|c|c|c|c|}
\hline 1 & 2 & 3 & 4 & 5 \\
\hline Strongly disagree & Disagree & Neutral & Agree & Strongly agree \\
\hline
\end{tabular}

14. The process of diagnosing the hearing loss was lengthy.

\begin{tabular}{|c|c|c|c|c|}
\hline 1 & 2 & 3 & 4 & 5 \\
\hline Strongly disagree & Disagree & Neutral & Agree & Strongly agree \\
\hline
\end{tabular}

15. How many sessions did it take to make the final diagnosis of your child's hearing loss?

\begin{tabular}{|l|l|}
\hline One & \\
\hline Two & \\
\hline Three & \\
\hline Four & \\
\hline Five & \\
\hline
\end{tabular}


16. The person making the diagnosis of your child's haring loss was confident in conveying the diagnosis. **

\begin{tabular}{|c|c|c|c|c|}
\hline 1 & 2 & 3 & 4 & 5 \\
\hline Strongly disagree & Disagree & Neutral & Agree & Strongly agree \\
\hline
\end{tabular}

17. We received sufficient information about the nature of our child's hearing loss from the person making the diagnosis. *

\begin{tabular}{|c|c|c|c|c|}
\hline 1 & 2 & 3 & 4 & 5 \\
\hline Strongly disagree & Disagree & Neutral & Agree & Strongly agree \\
\hline
\end{tabular}

18. We received sufficient information about the test results of our child's hearing loss from the person making the diagnosis. **

\begin{tabular}{|c|c|c|c|c|}
\hline 1 & 2 & 3 & 4 & 5 \\
\hline Strongly disagree & Disagree & Neutral & Agree & Strongly agree \\
\hline
\end{tabular}

19. We received sufficient information about rehabilitation options for our child from the person making the diagnosis. *

\begin{tabular}{|c|c|c|c|c|}
\hline 1 & 2 & 3 & 4 & 5 \\
\hline Strongly disagree & Disagree & Neutral & Agree & Strongly agree \\
\hline
\end{tabular}

20. We understood the diagnosis of the hearing loss. **

\begin{tabular}{|c|c|c|c|c|}
\hline 1 & 2 & 3 & 4 & 5 \\
\hline Strongly disagree & Disagree & Neutral & Agree & Strongly agree \\
\hline
\end{tabular}

21. We were guided by the person as to the next step to be taken. *

\begin{tabular}{|c|c|c|c|c|}
\hline 1 & 2 & 3 & 4 & 5 \\
\hline Strongly disagree & Disagree & Neutral & Agree & Strongly agree \\
\hline
\end{tabular}

22. We were given sufficient time to ask questions. **

\begin{tabular}{|c|c|c|c|c|}
\hline 1 & 2 & 3 & 4 & 5 \\
\hline Strongly disagree & Disagree & Neutral & Agree & Strongly agree \\
\hline
\end{tabular}

\section{Section 3: Hearing aids}

23. Does your child use amplification?

\begin{tabular}{|l|l|}
\hline Yes & \\
\hline No & \\
\hline
\end{tabular}

24. What type of amplification does your child use?

\begin{tabular}{|l|l|}
\hline Hearing aids & \\
\hline Cochlear implant - unilateral & \\
\hline Cochlear implant - binaural & \\
\hline Combination of above & \\
\hline None & \\
\hline
\end{tabular}

If yes, how old was your child when he/she was fitted with hearing aids?

\begin{tabular}{|c|c|}
\hline \multicolumn{2}{|c|}{ Hearing aids } \\
\hline Years & Months \\
\hline
\end{tabular}




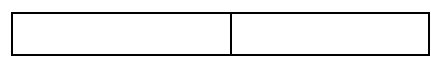

\begin{tabular}{|c|c|c|}
\cline { 2 - 3 } \multicolumn{1}{c|}{} & \multicolumn{2}{c|}{ Cochlear Implant } \\
\cline { 2 - 3 } \multicolumn{1}{c|}{} & Years & Months \\
\hline $1^{\text {st }}$ & & \\
\hline $2^{\text {nd }}$ & & \\
\hline
\end{tabular}

25. Our child's reaction to sound improved after being fitted with hearing aids. ${ }^{* *}$

\begin{tabular}{|c|c|c|c|c|}
\hline 1 & 2 & 3 & 4 & 5 \\
\hline Strongly disagree & Disagree & Neutral & Agree & Strongly agree \\
\hline
\end{tabular}

26. The hearing aids improved speech understanding for our child. **

\begin{tabular}{|c|c|c|c|c|}
\hline 1 & 2 & 3 & 4 & 5 \\
\hline Strongly disagree & Disagree & Neutral & Agree & Strongly agree \\
\hline
\end{tabular}

27. We would recommend the use of hearing aids to other parents with a child that has the same hearing impairment. **

\begin{tabular}{|c|c|c|c|c|}
\hline 1 & 2 & 3 & 4 & 5 \\
\hline Strongly disagree & Disagree & Neutral & Agree & Strongly agree \\
\hline
\end{tabular}

\section{Section 4: Parental experiences of the rehabilitation decision making process}

28. We were concerned about our child using a hearing instrument at first. **

\begin{tabular}{|c|c|c|c|c|}
\hline 1 & 2 & 3 & 4 & 5 \\
\hline Strongly disagree & Disagree & Neutral & Agree & Strongly agree \\
\hline
\end{tabular}

29. Our child wants to use his/her amplification. **

\begin{tabular}{|c|c|c|c|c|}
\hline 1 & 2 & 3 & 4 & 5 \\
\hline Strongly disagree & Disagree & Neutral & Agree & Strongly agree \\
\hline
\end{tabular}

30. We found the process of decision making about amplification difficult. **

\begin{tabular}{|c|c|c|c|c|}
\hline 1 & 2 & 3 & 4 & 5 \\
\hline Strongly disagree & Disagree & Neutral & Agree & Strongly agree \\
\hline
\end{tabular}

31. We often felt confused about conflicting information received during the decision making process about rehabilitation. **

\begin{tabular}{|c|c|c|c|c|}
\hline 1 & 2 & 3 & 4 & 5 \\
\hline Strongly disagree & Disagree & Neutral & Agree & Strongly agree \\
\hline
\end{tabular}

32. We felt that too many professionals were involved in the decision making process of rehabilitation. **

\begin{tabular}{|c|c|c|c|c|}
\hline 1 & 2 & 3 & 4 & 5 \\
\hline Strongly disagree & Disagree & Neutral & Agree & Strongly agree \\
\hline
\end{tabular}

Section 5: Parental needs for emotional support 
33. I need someone outside my family to talk about my hearing impaired child. **

\begin{tabular}{|c|c|c|c|c|}
\hline 1 & 2 & 3 & 4 & 5 \\
\hline Strongly disagree & Disagree & Neutral & Agree & Strongly agree \\
\hline
\end{tabular}

34. I need opportunities to meet with other parents of hearing impaired children. **

\begin{tabular}{|c|c|c|c|c|}
\hline 1 & 2 & 3 & 4 & 5 \\
\hline Strongly disagree & Disagree & Neutral & Agree & Strongly agree \\
\hline
\end{tabular}

35. I would like to be part of a support group of parents of children with hearing loss. *

\begin{tabular}{|c|c|c|c|c|}
\hline 1 & 2 & 3 & 4 & 5 \\
\hline Strongly disagree & Disagree & Neutral & Agree & Strongly agree \\
\hline
\end{tabular}

36. We need to talk to someone on how to handle and cope with our hearing impaired child. **

\begin{tabular}{|c|c|c|c|c|}
\hline 1 & 2 & 3 & 4 & 5 \\
\hline Strongly disagree & Disagree & Neutral & Agree & Strongly agree \\
\hline
\end{tabular}

37. My spouse needs help in understanding the hearing loss. **

\begin{tabular}{|c|c|c|c|c|}
\hline 1 & 2 & 3 & 4 & 5 \\
\hline Strongly disagree & Disagree & Neutral & Agree & Strongly agree \\
\hline
\end{tabular}

38. I need help to explain my child's condition to others. **

\begin{tabular}{|c|c|c|c|c|}
\hline 1 & 2 & 3 & 4 & 5 \\
\hline Strongly disagree & Disagree & Neutral & Agree & Strongly agree \\
\hline
\end{tabular}

39. I need help in coping with the emotional aspects of having a child with a hearing loss. ${ }^{* \star}$

\begin{tabular}{|c|c|c|c|c|}
\hline 1 & 2 & 3 & 4 & 5 \\
\hline Strongly disagree & Disagree & Neutral & Agree & Strongly agree \\
\hline
\end{tabular}

\section{Section 6: Parental need for information}

40. I would like information about my child's hearing loss. *

\begin{tabular}{|c|c|c|c|c|}
\hline 1 & 2 & 3 & 4 & 5 \\
\hline Strongly disagree & Disagree & Neutral & Agree & Strongly agree \\
\hline
\end{tabular}

41. I would like information about specific types of hearing loss. **

\begin{tabular}{|c|c|c|c|c|}
\hline 1 & 2 & 3 & 4 & 5 \\
\hline Strongly disagree & Disagree & Neutral & Agree & Strongly agree \\
\hline
\end{tabular}

42. I would like information about what to expect of my hearing impaired child for the future. **

\begin{tabular}{|c|c|c|c|c|}
\hline 1 & 2 & 3 & 4 & 5 \\
\hline Strongly disagree & Disagree & Neutral & Agree & Strongly agree \\
\hline
\end{tabular}

43. I would like information about communication options (sign language, alternative communication methods etc.). **

\begin{tabular}{|c|c|c|c|c|}
\hline 1 & 2 & 3 & 4 & 5 \\
\hline Strongly disagree & Disagree & Neutral & Agree & Strongly agree \\
\hline
\end{tabular}

44. I would like information about intervention services/programs available for my child. ** 


\begin{tabular}{|c|c|c|c|c|}
\hline 1 & 2 & 3 & 4 & 5 \\
\hline Strongly disagree & Disagree & Neutral & Agree & Strongly agree \\
\hline
\end{tabular}

45. I would like information about educational options for my child. *

\begin{tabular}{|c|c|c|c|c|}
\hline 1 & 2 & 3 & 4 & 5 \\
\hline Strongly disagree & Disagree & Neutral & Agree & Strongly agree \\
\hline
\end{tabular}

** Questions used for statistical analysis within a group

\begin{tabular}{|l|}
\hline \multicolumn{2}{|c|}{ For office use only } \\
\hline Respondent number \\
\hline Type of hearing loss \\
\hline SNHL \\
ANSD \\
\cline { 2 - 2 }
\end{tabular}

